\title{
A QUESTÃO SOCIAL EM HANNAH ARENDT
}

Odilio Alves AGUIAR ${ }^{1}$

- RESUMO: Aborda a questão social no interior do surgimento da esfera social na modernidade e suas implicações na constituição e derrocada da esfera pública no mundo contemporâneo.

- PALAVRAS-CHAVE: Questão social; esfera pública; labor; necessidade; violência.

A questão social é um tema de enfrentamento difícil em Hannah Arendt. Difícil porque a categoria do social na autora não tem o assentimento que a faz vigorar e constituir pressuposto científico, notadamente no Brasil, onde a influência do marxismo nessa área do saber, pelo menos num certo período, é inquestionável. Atesta isso o fato de as discussões sobre outras dimensões da vida (cultural, imaginária, espacial, temporal, etc) serem concebidas como inseridas no campo social, entendido equivocadamente, segundo Arendt, como esfera do artifício, construção humano-cultural, em contraposição à dimensão natural. Assim sendo, como Arendt abordou criticamente a questão social, isso implica confrontar-se com um certo tabu, com uma sacralização que ainda prevalece entre os que "ontologizam" o social e tomam o tema da exploração econômica como o fundamento dos seus trabalhos acadêmicos e, a partir daí, buscam influenciar os programas político-partidários e as ações governamentais. A mutação aparente desse fundamento em tem-

1 Departamento de Filosofia - Universidade Federal do Ceará (UFC).E-mail:odílio@uol.com.br 
pos de crises dos paradigmas, quando outros discursos, por exemplo, o dos excluídos, contrabandeado da religião, não é suficiente para indicar uma abertura para outros horizontes teóricos. Se a piedade ou o cerceamento ideológico é algo maléfico em política, porque, na visão de Arendt, empobrece o conceito de solidariedade, muito pior é o estreitamento que ele causa ao trabalho intelectual.

Se a abordagem arendtiana pode gerar polêmica, pois leva a uma difícil contraposição aos arautos da questão social, sua tematização se torna difícil, também, porque exige a explicitação da posição arendtiana sobre o assunto, uma postura lacônica, como veremos, bem como a demonstração de que existe algo mais importante a merecer nossa atenção. A quaestio facti, a inegável importância e urgência da questão social, reclama, para um questionamento que venha a transcendê-la, a questão de validade, uma quaestio juris.

Antes de adentrarmos essa questão da validade, vale dizer que achamos equivocada a posição dos que defendem o argumento de que a concepção de Arendt sobre a questão social é perpassada por profunda insensibilidade para com os explorados economicamente e que há uma desconsideração da pobreza na autora. Trata-se, na verdade, como veremos, da perspectiva que deveria, segundo Arendt, ser considerada importante e, por isso, iluminada pela luz do pensamento. Se não era animosidade para com os pobres, como entender a posição arendtiana?

A concepção arendtiana questiona o senso comum teórico que confunde o social com o artifício, a cultura humana no sentido alargado e, principalmente, com o político, uma confusão antiga e que ainda hoje ressoa na atual luta pelo social em contraposição ao econômico. Em Arendt, social e econômico são a mesma coisa, um não existe sem o outro. Todas essas questões remetem à compreensão arendtiana da categoria do social. Podemos dizer que o problema maior de Arendt não é tanto com a questão social, mas com a esfera social a partir da qual surgiu e é compreendida a questão social. Qual a compreensão, pois, que Arendt tem do social?

Para compreender esta categoria, Arendt recorre à concepção filosófica de teor clássico no cotejamento fenomenológico das atividades humanas. De acordo com essa visão, os seres humanos se distinguem dos animais porque vivenciam a sua condição humana por intermédio de modos de vida que podem ser distinguidos em vita activa e vita contemplatativa. A novidade da categoria do social é inserida numa fenomenologia da vita activa na sua obra A Condição Humana, mas o tema aparece em várias outras. Poderíamos nomear a terceira parte de Ori- 
gens do Totalitarismo, no qual é possível perscrutar uma certa relação entre a questão social e as experiências totalitárias; em Entre o Passado e o Futuro, principalmente no capítulo "A Crise na Cultura: sua importância social e política", onde contrapõe o belo ao útil e funcional e apresenta a funcionalização como o critério próprio ao domínio do social. De forma direta, a relação entre a categoria do social e a questão social pode ser observada no capítulo "A questão social" do livro Da Revolução. Nesse texto, Arendt argumenta que a assunção da questão social como justificativa e critério revolucionário provocou a corrupção e levou à decadência quase todos movimentos revolucionários modernos.

O tema da vita contemplativa em sua relação com a vita activa foi abordado diretamente apenas no final da vida de Arendt. Ela morreu quando escrevia a terceira parte da obra $\mathbf{A}$ Vida do Espírito. A motivação desse livro, sem dúvidas, pode ser atribuída à dificuldade de, nas sociedades contemporâneas, se exercer a faculdade do juízo, uma faculdade intimamente relacionada à capacidade de pensar, forma apropriada do pensamento se manifestar no mundo. Na sociabilidade atual, na qual a esfera e os padrões provenientes do social estão em vigor, o exercício da faculdade de julgar é dificultado, prevalecendo um horizonte meramente funcional e condicionado. Eichmann, o carrasco nazista que enviou os judeus para os campos de concentração, é o protótipo, para Arendt, do homem contemporâneo que age sem julgar, como se fosse uma coisa na engrenagem social e institucional, condicionado apenas pelos interesses funcionais. Esse tipo de homem age como o cão de Pavlov, treinado para salivar mesmo sem ter fome. Do mesmo modo, sem motivação alguma, desfeito da habilidade de julgar, o homem pode possibilitar ou realizar os maiores males. A isso Arendt chamou de a banalização do mal.

$\mathrm{Na}$ esteira da visão grega antiga, Arendt entende vita activa relacionando-a às esferas nas quais estão localizadas as atividades humanas: a esfera privada e a pública. Aqui é preciso cuidado para não confundirmos essa conceituação com a abordagem liberal nem como possuindo características predicativas. A retomada da concepção antiga indica que esses conceitos possuem apenas valor heurístico, tentam apenas apresentar outra possibilidade de se pensar nos atuais modos de vida. $\mathrm{Na}$ abordagem liberal, o público não é o importante, vem pensado apenas como a serviço dos interesses privados. Na perspectiva antiga, a esfera pública é o espaço em que entram somente ações (praxis) e palavras (lexis) que dignificam o homem, que o tornam distinto do animal humano. Nessa esfera, o homem adentra como ser livre, capaz de tomar atitudes e agir espontaneamente, sem o constrangimento das necessidades 
ou forma outra de coação. Dimensão do reconhecimento, a política oferece um espaço na memória da comunidade para a imortalização dos homens como seres singulares. ${ }^{2}$ Já a esfera privada é a dimensão em que os homens, privados do mundo, exercem atividades constrangidos pelo fato de serem animais como os demais animais (labor) ou, então, realizam atividades cuja execução exige a retirada do mundo, mesmo que retornem e necessitem do mundo público para adquirir realidade, como no caso da arte, do trabalho (work) e a atividade do pensamento.

A esfera social é o resultado de um certo hibridismo entre as esferas privada e pública e se põe na perspectiva que, segundo Arendt, constituiu uma característica específica da modernidade que foi a resolução e o empenho dos homens em se desfazerem de uma vez do constrangimento que a dimensão da reprodução biológica impõe a todos. É em função dessa perspectiva que vai surgir o social. ${ }^{3} \mathrm{O}$ social retirou da esfera política a dimensão de publicidade e da esfera privada a ocupação com a esfera das necessidades. Com a ascensão do social, as atividades executadas privadamente passaram a ter importância pública e o que era típico do público passou a ser um luxo. É como o pássaro da mitologia grega que esconde a rica plumagem e expõe as entranhas. A tentativa de gerar condições de abundância para a reprodução biológica fez com que o labor, atividade na qual os homens produzem e reproduzem as condições de sobrevivência, adquirisse um status impensável na visão tradicional. É como se todos os homens e toda a sociedade, ao privilegiarem o econômico, acabassem originando uma situação geral de escravização, o fim da liberdade necessária para a constituição de um mundo comum. Fracassou a utopia de que a sociedade, ao se engajar exclusivamente na geração de abundância, iria produzir uma situação de liberdade, uma vez que a "laborização" invadiu também o tempo livre como, por exemplo, na forma da industrialização do entretenimento. O labor é, assim, a atividade típica do social. ${ }^{4}$ Arendt verifica que houve uma "laborização" geral das outras atividades: tudo passou a ser visto em função do progresso, da geração da abundância. Consumir, algo que se exerce passivamente, passou a ser a única possibilidade nesse tipo

2 A representação da imortalidade foi desligada das experiências intersubjetivas dos homens e o futuro, a história se tornou uma questão do progresso. Essa perspectiva encontra-se muito bem criticada em "A Morte a Imortalidade" de Claude Lefort, in Pensando o Político, trad. Eliana M. Souza, Paz e Terra, 1991, p.p. 297-326.

3 Cf. ARENDT, H.: "The Rise of the Social", in A Condição Humana, p.p. 47 - 59.

4 Cf. ARENDT, H.: "A Derrota do Homo Faber e o Princípio Felicidade" e "A Vitória do Animal Laborans" in idem, p.p. 317-326 e 333-338. 
de sociedade. A política, reduzida a governo, passou a se restringir em elaborar e administrar estratégias para o livre desenvolvimento do progresso; o trabalho como capacidade de oferecer objetos e artefatos que tornassem o mundo um abrigo em relação à natureza transformou-se em mera função; mesmo a arte, de atividade encarregada de provocar a reconciliação crítica com o mundo e de embelezá-lo, transformou-se em instância apaziguadora e de entretenimento.

Desse modo, o social, em Arendt, não se relaciona à esfera da cultura e artifício humano, ao contrário, trata-se da esfera das atividades humanas que mais aproxima o homem da sua dimensão natural (animal), justamente porque está empenhada na manutenção da vida entendida biologicamente e, por isso, não deixa os vestígios que caracterizam a esfera da cultura e do artifício humano.

O resultado da ascensão do social foi o surgimento das sociedades de massa, nas quais, segundo Arendt, os homens são reduzidos à função de suporte do ciclo vital a partir de onde se tornou possível o seu controle. Por via da funcionalização e do consumo, foram aumentadas a previsão, a padronização e o controle sobre a capacidade humana de agir e transformar. O enorme progresso tecnológico apenas corrobora essa "biologização" da vida, uma vez que o buscado, a abundância, é uma forma de fazer com que a natureza invada o campo do artifício, fazendo-o perder a sua característica fundamental: a de obstar o poder coercitivo constrangedor da natureza sobre o mundo humano, potencializando, assim a descartabilidade [superfluousness] dos homens como tais. A funcionalização e a massificação dos homens ensejam a perda da sua especificidade, o banimento da dimensão da autarquia humana [autarqueia]. O processo de massificação despoja os seres humanos de suas qualidades humanas, torna-os intercambiáveis e, acima de tudo, supérfluos. ${ }^{5}$

Segundo Arendt, a partir da glorificação do social e do nascimento da sociabilidade massificada surgiu um grande mal-entendido tremendamente alimentado pela tradição: trata-se da confusão do social com o político. Isso já aparece na tradução que os medievais fizeram da expressão Zoon Politikon como animal socialis. A partir daí adentrou o Ocidente a idéia de que qualquer comunidade é uma formação política. Na verdade, essa tradução já está fortemente influenciada pelo cristianismo. Tomás de Aquino é seu arauto. Ela não acolhe o sentido do termo romano societas (associação), no qual se mantém a lacuna entre natureza (espé-

5 Cf. KOHN, Jerome. "Evil and Plurality", in Hannah Arendt Twenty Years Later, ed. Larry May e Jerome Kohn, Londres: MIT Press, 1996, p.p. 147-178. 
cie) e existência humana (indivíduo), a possibilidade da diferenciação, da política como algo pactuado, promessa mútua. Subjaz à tradução tomista a compreensão da comunidade política como uma fraternidade, uma família, isto é, indiferenciada, com interesse único. Não há um mundo, uma polis interpondo-se às pessoas. ${ }^{6}$ É essa acepção que se faz presente no conceito moderno de sociedade, na qual reina a unidade muda, consenso anônimo, opinião única e de ninguém, inviabilizadora do aparecimento de comunidades políticas que tornem possíveis as relações entre pessoas e conexões entre seres humanos livres e ativos. ${ }^{7}$

Embora o embaralhamento nos termos indique uma tendência a assimilar o político no social, na tradição, no entanto, o começo real da moderna categoria do social se deu nas cortes no final do Ancien Régime e se explicita nos Estados nacionais modernos. Foi nas sociedades das cortes que pela primeira vez se eliminou a barreira entre doméstico e público e, com a sua rígida etiqueta, propôs-se uma normalização do comportamento dos indivíduos. Pela primeira vez na vida pública, as posições e funções sociais passaram a ter preeminência sobre as ações dos indivíduos. Era a corte, como posteriormente a sociedade pertencente ao Estado-Nação, a atribuir a função que o indivíduo deveria realizar. Também como na corte, com a venda dos títulos nobiliárquicos, é que a preocupação com a aquisição, a riqueza, passou a ser mais importante do que a honra e o reconhecimento pessoal, antecipando assim a posterior preocupação de toda sociedade com o progresso e a abundância. ${ }^{8}$

6 Já na sua tese de doutorado, Arendt percebera o caráter não mundano do cristianismo quando trata da relação entre a fé do cristão e o necessário engajamento político, no qual todos são concebidos como próximos e se é guiado pelo amor, segundo ela, em A Condição Humana, o mais acósmico dos sentimentos. Cf. "Vita Socialis" in Le Concepte du Amour, trad. fr., 1991, p.p. 91 108. A esse respeito, Arendt escreve em Was ist Politik? p. 63 que, com o cristianismo, a liberdade da política deixa de ser uma coisa apenas do filósofo; agora toda a multidão é liberada da política para se concentrar no cuidado com a alma. Assim é deixado de lado o cuidado com o mundo, a preocupação em imortalizar o próprio nome.

7 O aparecimento de um interesse absoluto invalida a livre participação dos cidadãos e o surgimento de comunidades políticas. Essa questão encontra-se amplamente tematizada em Da Revolução. Sobre a categoria do social em Arendt cf. ABRANCHES, Antonio: in Antropologia da Vita Activa em H. Arendt, cap. "Sobre o Conceito de Sociedade", Puc, RJ, p.p. 63 - 75.

8 A primeira manifestação do hibridismo entre público e privado acontece com a solenização da vida doméstica de Luis XIV e tem sua maneira intermendiária no Estado-Nação, no qual os problemas da administração da sobrevivência dos seus membros se constituem em questão única da política e sua forma acabada nas contemporâneas sociedades de massas, nas quais se atingiu a plena funcionalização da vida das pessoas. Sobre o hibridismo e a etiqueta nas cortes cf. ARENDT, H.: $\underline{A}$ Condição Humana, p. 50 e Entre o Passado e o Futuro. 251, e de RIBEIRO, Renato J. A Etiqueta no Antigo Regime, particularmente o capítulo "Quem é Quem". Brasiliense, 1983, p.p. 72 - 95. 
Social é então, para Arendt, a forma de vida que surgiu com a modernidade e na qual resultam privilegiadas a socialização e a funcionalização das atividades humanas, uma vez que o biológico priorizado impõe uma forma de organização dos homens em que eles não passam de meros meios, funções, para realização do progresso e, assim, como tais, como seres singulares, se tornam supérfluos. Essa é a razão da animosidade de Arendt para com a categoria do social. ${ }^{9}$ Isso significa o fim da liberdade para agir, começar algo novo, fundar comunidades, e o cerceamento da dimensão espiritual, da capacidade de descondicionamento inerente ao exercício da faculdade de pensar.

A partir da crítica à tradução de Zoon Politikon é possível rastrear, segundo Arendt, uma estreita conexão entre a ascensão do social e a transformação do conceito de sociedade civil. O conceito de sociedade civil que, inicialmente, tanto na sua origem romana (societas civilis) como entre os primeiros contratualistas (estado civil) indicava a dimensão política propriamente dita, foi alterado, inclusive como figura jurídica, a partir da ascensão do social nas modernas sociedades burguesas. ${ }^{10}$ A partir de então, sociedade civil deixou de significar o campo em que a força e a violência naturais eram limitadas e superadas pela dimensão de civilidade e passou a traduzir a "historicização" e prolongamento do estado natural, o reino da sobrevivência. Em Hegel e Marx, por exemplo, indica o campo da regulação das relações econômicas, da propriedade, etc. ${ }^{11}$ Por mais alterações que se verifiquem no conceito de sociedade civil, como, por exemplo, a partir da influência da concepção de Gramsci ou do surgimento e poder das ONGs, parece que algo permanece inalterado na concepção de sociedade civil sob os auspícios do social. Isto porque é a essa esfera que ainda hoje são relacionadas a legitimação e a limitação do poder. A sociedade civil como esfera de legitimação se expressa na "opinião pública". Isto indica tanto a clivagem entre poder e legitimação como o controle da política a partir dos interesses privados. Opinião pública não significa um instituto por meio do qual a troca pública de opinião se realiza, mas como um interesse mudo e anônimo pode se alçar a interesse de todos. Essa mudeza - anonimato

9 Cf. BENHABIB, Seyla. The Reluctante Modernism of Hannah Arendt. Thousand Oakes: Sage Publications, 1996.

10 Cf. HABERMAS, Mudança Estrutural da Esfera Pública, trad. Flávio R. Kothe. Rio de Janeiro: Tempo Brasileiro, 1984

11 Cf. BOBBIO, Norberto et al. "Sociedade Civil", in: Dicionário de Política, vol.2, UNB, p.p. 12061210. 
e generalidade abstrata - vem sempre expressa na filiação da opinião pública ao social.

A compreensão da categoria de social em Arendt, assim, se faz em conexão com outros conceitos: vita activa, público, privado, propriedade, revolução industrial e tecnológica, massificação, violência, sociedade civil, opinião pública, piedade, revolução etc. Se é possível perceber o engendramento da esfera social e o surgimento do conceito a ela relacionado já na Idade Média, nas sociedades das cortes, na reforma protestante e na Revolução Industrial, no entanto, foi na Revolução Francesa e no surgimento da questão social como sua instância de justificação que a esfera social assumiu importância pública. Assim sendo, é possível passarmos para o exame direto da questão social, como está posta no capítulo do mesmo nome no livro Da Revolução.

O livro em pauta é o único lugar em que Arendt tematiza explicitamente a questão social. Nessa obra, a autora aborda as experiências revolucionárias modernas e mostra como a Revolução Francesa, com seu jacobinismo, tornou-se padrão para as revoluções contemporâneas. O contexto das transformações das revoluções em guerra de eliminação do inimigo interno, antes pensada apenas para guerras externas e, portanto, a ampliação da violência, cujo ápice é o terror, recebeu significativa contribuição com a entrada da questão social no cenário revolucionário. Arendt inicialmente elogia a reivindicação de liberdade e a tentativa de organização de uma nova forma política, cujo poder partia do consentimento do povo, impedindo assim o alastramento da opressão e viabilizando a liberdade para a maioria, verificada, por exemplo, na Comuna de Paris. Essa experiência foi solapada, segundo Arendt, porque a liberação tomou o lugar da liberdade no intento de justificar a revolução.

Liberação é o processo por via do qual se procura eliminar o constrangimento imposto pelo ciclo vital. O povo, inicialmente entendido como o conjunto dos cidadãos impossibilitado de participar dos assuntos públicos pela opressão do centralismo monárquico, passou a significar a multidão faminta, despossuída e sofredora. Na medida em que a necessidade tomou lugar da liberdade como legitimação da revolução, a urgência da questão social, vale dizer, da pobreza e da fome, tornou insignificante a questão da liberdade. A opressão deixou de ser de homens sobre homens e passou a ser entendida como da natureza sobre os homens. Para Arendt, a superação da opressão realiza-se através da constituição de uma nova forma de governo, na qual os cidadãos possam ter poder efetivo. Os problemas atinentes à liberação obtêm sua solução não na política, pois a escassez é resolvida com abundância. O 
contato com a questão social fez com que a revolução absolutizasse a liberação, a superação da penúria e da miséria como finalidade revolucionária. A invasão da cena pública pela massa dos miseráveis exigindo a solução para sua pobreza transformou-se em necessidade histórica, numa avalanche que passou a desconhecer qualquer limitação. Diante dessa situação, qualquer instituição, qualquer permanência é considerada luxo. A liberação da necessidade passou a ter prioridade sobre a edificação da liberdade e o resultado foi a instituição da revolução permanente, da violência ilimitada, o terror, e não a fundação de uma nova constitutio libertatis, um corpo político de iguais. Arendt pensa na revolução não como instrumento da redenção da condição humana, da finitude. Querer emancipar o homem do constrangimento da necessidade encaminha-se em direção a uma concepção "infinitista" da revolução. A questão social como saída revolucionária única aponta para solução revolucionária totalizante. Arendt se põe no campo revolucionário, mas sem resvalar para o "infinitismo". As possibilidades revolucionárias em Arendt não ensejam construir um tipo de homem, mas instaurar um campo de liberdade onde a humanidade, na sua rica diversidade, possa ser preservada. Entre os vários assuntos humanos, um deles, entre tantos, pode ser a questão social. Vale dizer, para Arendt, a revolução, assim como qualquer assunto humano, não pode ser pensada com saída única ou realizada dentro de um espírito de solução total.

O problema de Arendt não é com a questão social, mas com o fato de sua absolutização e de sua resolução como objetivo político acarretar a própria eliminação da política. Transformada em necessidade histórica, a questão social recebeu legitimidade para questionar qualquer lei ou instituição que não reconhecesse e se guiasse pela sua urgência. Essa urgência não se adapta aos demorados e argumentativos processos de persuasão e negociação próprios da esfera política. A necessidade se impõe, não exige argumentação. O desafio para Arendt era construir uma novus ordo saeculorum capaz de dar um sentido à vida para além da sua determinação biológica. Arendt chega a se referir elogiosamente a Lenin que disse, no primeiro momento da revolução, que o objetivo revolucionário era "eletrificação mais sovietes". Eletrificação significava a resolução da pobreza pela tecnologia, e sovietes significava a superação da tirania por uma nova organização política, campo para a convivência entre os homens sem constrangimentos, esfera da liberdade. Evidentemente isso não durou muito, pois o partido bolchevique passou a dar as cartas tanto no campo político, sobredeterminando os sovietes, como no campo econômico. 
Esse conceito de necessidade histórica possibilitou uma articulação de certa forma sofisticada, uma vez que tornou viável a aproximação com a filosofia praticada pela tradição que ambicionava tematizar o absoluto. A filosofia típica da esfera social é a filosofia teleológica da história, na qual paira uma concepção determinista do tempo e da ação humana. O sujeito universal da Filosofia passou a ser "entificado" na humanidade social, na maioria expropriada da população. Dotado de legitimidade absoluta, a revolução com facilidade descambou para o terror. A fidelidade aos malheureux, a virtude de deixar de lado os próprios interesses e se ligar aos sofrimentos dos infelizes constituiu-se no critério da caça aos inimigos objetivos, não mais externos, mas dentro da próprio casa.

Conforme Arendt, com a questão social, o sentimento se torna mais significante do que a opinião na esfera política. A piedade, a decisão de unir silenciosamente a própria vontade à vontade da humanidade sofredora transformou-se numa virtude política. Com a piedade, o turbilhão dos sentimentos pôde invadir a política e provocar as maiores crueldades. "Pour pitié, pour amour l'humanité, soyes unhumains!" Essa palavra de ordem jacobina traduz a potência da violência dos sentimentos no interior da política. Em seu nome, justifica-se a amputação dos membros para salvar a saúde da comunidade; em nome dos "sofredores" justifica-se a morte dos "egoístas". Em seu nome é fácil e válida a passagem do engajamento (engagement) para a ira (enragés). A violência, assim, apenas imita o processo violento com que o constrangimento das necessidades se impõe. Para Arendt, a piedade é a perversão da solidariedade, esta sim uma virtude política. Na solidariedade está em xeque o aceite da posição do outro manifesta numa opinião. O outro entra não como um necessitado, mas como um igual, com capacidade de falar, como um cidadão, nem que seja em termos potenciais.

Com a ascensão da questão social, os direitos humanos passaram a ser um tema ligado ao direito civil e não ao direito público. A dignidade pressuposta nessa concepção é natural, biológica, na qual o homem não é visto como detentor de uma personalidade jurídica, como capaz de agir e falar, mas como um ser ao qual deve ser garantida a vida na sua mudeza naturalística. A fonte de poder deixou de ser o cidadão e passou a ser o homem natural. Os direitos às condições para as funções possibilitadoras da manutenção da vida biológica absolutizadas eliminou ou tornou sem importância o pertencer a um corpo político, o direito à liberdade de agir e participar. Esse é o sentido contido na defesa 
arendtiana do "direito a ter direitos" e na crítica à concepção naturalista dos direitos humanos presente em Origens do Totalitarismo.

A luta de Arendt não é contra o empenho da sociedade para resolver a questão social, mas com a repercussão desse empenho na política. Isto é, Arendt não é contra a questão social, mas a favor da grandeza humana. Esta se manifesta na forma criativa de produzir o mundo e no deslinde da questão social sem se fechar no constrangimento natural. Para ela, a questão social pode ser resolvida num contexto de tirania, ditadura e até motivar o totalitarismo. Em segundo lugar, a abundância não implica surgimento de cidadãos. Ao contrário, as sociedades consumistas estão mostrando uma sofistificação enorme na manutenção dos homens como meros consumidores. No entender de Arendt, a superação ou atenuação da necessidade não implica o surgimento ou construção da esfera da liberdade, em formas mais civilizadas de convivência. O que Arendt detecta é a expansão da solidão e da alienação nas sociedades abundantes. Com isso ela quer argumentar que não vale a pena sacrificar a grandeza do homem, a capacidade humana de ultrapassar a dimensão natural e articular a convivência em palavras e pactos em vista do deslindamento da questão social. Para ela, a violência na política tem uma validade limitada, justifica-se apenas no momento da fundação do corpo político, na superação do reino da força bruta como padrão das relações humanas.

A absolutização da questão social ocasionou enorme estreitamento do conceito de Bem Comum. O Bem Comum transformou-se nos elementos necessários ao bem-estar da população. Bem Comum passou a ser coisas e não o mundo comum que nasce da convivência livre dos cidadãos, campo da memória e imortalização. A diminuição do estatuto do Bem Comum, e sua transformação em "vestuário, alimentação" e condições para a reprodução da população, levou também ao empobrecimento da concepção de propriedade sob a égide da esfera social. De local de proteção e sinalizadora de um lugar no mundo (propriety, imóvel), transformou-se em meio para a acumulação de riqueza (property, consumptibiles). ${ }^{12}$ Com a subserviência da política ao social, a propriedade deixou de ser uma condição para a vida pública e passou a exigir da esfera pública as condições para que, enquanto for meio, possa dispor-se a serviço da acumulação, da abundância e da especulação. Foi esse entendimento que levou ao desapossamento e à coletivização das

12 Cf. ARENDT, H. A Condição Humana, p.p. 79 -80. 
residências e bens pessoais na experiência soviética. Qualquer posse era entendida como egoísmo e obstáculo à fraternidade universal.

Finalizando, podemos dizer que, embora não seja contra a questão social, Arendt se opõe, no entanto, aos defensores do sacrifício da esfera política para se resolver o problema da escassez. O pressuposto do seu pensamento não é a economia, mas a idéia de que a grandeza humana, a excelência máxima (aretê) que os homens podem alcançar, realiza-se na convivência e nas relações humanas, domínio apropriado para se mostrar o quem, forma por meio da qual a vida se singulariza como humana e não no exercício das funções sociais. Esse espaço é relativo, constitui-se no consentimento forjado na pluralidade de seres singulares. Essa é a perspectiva da validade a partir da qual a quaestio facti da questão social é apreciada por Arendt. O sacrifício desse espaço em nome da questão social não vai originar a sua resolução, uma vez que as sociedades de abundância não formam cidadãos, mas consumidores e, além do mais, absolutizada, a questão social tende a pôr em movimento uma violência sem limite, justificada pela violência com que o próprio ciclo vital constrange os seres humanos, um ciclo que se repete ad infinitum, pois constitutivo da condição humana.

A solução que é possível vislumbrar em Arendt para a questão social é lacônica. Sua preocupação era a recuperação da dignidade da política. Essa talvez seja a razão da pouca reflexão dedicada ao assunto. Do pouco que ela disse, podemos entender que, para a filósofa, a questão social era de solução técnica. O desenvolvimento tecnológico é a chave para superar a escassez. Arendt concebia a tecnologia como uma esfera neutra e coisa de especialista; uma visão talvez ingênua, pelo menos para os nossos tempos. A questão social, assim, é concebida como uma questão de planejamento, administração e conhecimento especializado, passível de solução não a partir da troca de opinião e deliberação pública, mas no interior de uma perspectiva autoritária inerente à dimensão estratégica e administrativa. O problema é que a transformação da política em administração no mundo moderno, tão profundamente criticado por Arendt, ensejou a politização da tecnologia e do conhecimento especializado. Vivemos num tempo em que é praticada a deliberação, por uns poucos, é verdade, das possíveis soluções técnicas ou na qual estas vêm submetidas ao tacão do interesse econômico-especulativo. Outra coisa em que Arendt não mostra consciência é no fato de que a tecnologia não se porta como uma esfera neutra, ao contrário, vários estudos mostram que a incidência da tecnologia nos modos de vida nem sempre favorece o intercâmbio das pessoas. 
Além de, na maioria das vezes, obstar as relações diretas, o desenvolvimento tecnológico provoca, em muitos países, não a resolução da questão social, mas o seu acirramento em função da descartabilidade de um contingente enorme da mão-de-obra do mercado de trabalho. Centrada na questão política, nem de longe esse tipo de assunto mereceu a atenção da brilhante e original inteligência arendtiana, o que significa a existência de alguns limites na sua perspectiva.

AGUIAR, O. A. The social question in Hannah Arendt. Trans/Form/Ação, (São Paulo), v.27 (2), p.7-20, 2004.

- ABSTRACT: Approaches the social question inside the rise of social realm in the modernity and the implications of that in the constitution and decadence of the public realm in contemporary world.

- KEYWORDS: Social question; public realm; labor; necessity; violence.

\section{Referências bibliográficas}

ABRANCHES, A. Antropologia da Vita Activa em Hannah Arendt. Dissertação de Mestrado. Rio de Janeiro: PUC, 1986.

ARENDT, H. Origens do Totalitarismo. Trad. Roberto Raposo. São Paulo: Companhia das Letras, 1990.

A Condição Humana. Trad. de Roberto Raposo, Rio de Janeiro: Forense, 1983.

Entre o Passado e o Futuro. Trad. de Mauro Barbosa de Almeida. São Paulo: Perspectiva, 1988.

Qu ¿est-ce que la Politique? Tradução francesa de Sylvie CourtineDenamy. Paris: Du Seuil, 1993.

Le Concept d Lamour chez Saint Augustin. Trad. de Anne Sophie Astrup. Paris: Deux Temps/Tierce, 1991.

Da Revolução. Trad. de Fernando Didimo. São Paulo: Ática-UNB, 1990.

BENHABIB, S. The Reluctante modernism of Hannah Arendt. N. York: Sage Publications, 1996. 
BOBBIO, N. et al. Dicionário de Política. Brasília: UNB, 1989.

HABERMAS, J. Mudança Estrutural da Esfera Pública. Trad. Flávio Kothe. Rio de Janeiro: Tempo Brasileiro, 1984.

KOHN, J. et MAY L.. Hannah Arendt Twenty Years Later. Londres: Mit Press, 1996.

RIBEIRO, Renato Janine. A Etiqueta no Antigo Regime. São Paulo: Brasiliense, 1983. 